\title{
Preoperative Anxiety in Patients Undergoing Thoracic Surgery
}

\author{
Saricam Murat ${ }^{1}$ \\ ${ }^{1}$ Department of Thoracic Surgery, Namik Kemal University, Tekirdag, Turkey.
}

ABSTRACT

\section{BACKGROUND}

Preoperative anxiety is closely associated with poor surgical outcomes and potential complications. This study aimed to investigate the risk factors affecting the level of anxiety in patients who were candidates for thoracic surgery.

\section{METHODS}

A prospective study was conducted among 100 patients who would undergo thoracic surgery under general anaesthesia for both malignant and benign diseases. Data concerning age, gender, educational status, length of preoperative hospital stay, past surgical history and indication of the proposed operation were collected, and preoperative anxiety was graded via State-Trait Anxiety Inventory (STAI) for each patient.

\section{RESULTS}

Among a total of 65 male and 35 female patients, mean age was $54.1 \pm 11.5$ years. High level of preoperative anxiety was presented in $56 \%$ of the patients. Statistical analysis revealed that the higher level of state anxiety was associated with male sex, young age, existence of past surgical history, benign disease and high educational status $(\mathrm{p}<0.05)$; whereas, longer length of preoperative hospital stay was not related with a significant difference in the state anxiety level ( $p>0.005)$.

\section{CONCLUSIONS}

Regarding the conflicting findings obtained from recent reports and this study, individual assessment of each surgical patient is necessary to perform a valid risk analysis of preoperative anxiety.

\section{KEY WORDS}

Preoperative Anxiety, Risk Factors, Thoracic Surgery, State Anxiety.
Corresponding Author:

Murat Saricam,

Department of Thoracic Surgery,

Namik Kemal University,

Suleymanpasa-59010,

Tekirdag, Turkey.

E-mail:msaricam@nku.edu.tr

DOI: $10.14260 / j e m d s / 2020 / 218$

Financial or Other Competing Interests: None.

How to Cite This Article:

Saricam M. Preoperative anxiety in patients undergoing thoracic surgery. J. Evolution Med. Dent. Sci. 2020;9(13): 1015-1018, DOI:

10.14260/jemds/2020/218

Submission 20-01-2020,

Peer Review 06-03-2020,

Acceptance 12-03-2020,

Published 30-03-2020.

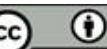




\section{BACKGROUND}

Anxiety is described as an emotion of worry, unease, fear and tension about an uncertain outcome. ${ }^{1}$ Perioperative period is a distressing event which usually induces emotional and cognitive alterations. Experience of anxiety before a surgery is mostly considered as a usual patient response whereas extended level of preoperative anxiety results in a delay of healing and a poor recovery. ${ }^{2}$ Preoperative anxiety has been reported to affect surgical patients at a rate up to $80 \%$ and result in large number of postoperative complications including pain, nausea, cardiovascular disorders and increased risk of infection..$^{3-6}$

The degree of each patient's reaction to preoperative anxiety ranges widely depending on many factors such as age, gender, educational status, past surgical experiences, current health status, indication of the proposed surgery and natural susceptibility to anxiety. ${ }^{7-9}$ The objective of this study was to assess the prevalence preoperative anxiety and causative factors among the adult patients undergoing thoracic surgery.

\section{METHODS}

Following the approval of Faculty's Ethic Committee, a crosssectional, questionnaire-based study was conducted to include 100 patients who would undergo elective thoracic surgery under general anaesthesia for both benign and malignant diseases resulting from non-traumatic aetiology between April and August 2018. This study included patients aged over 18 years who had consented to reply the questionnaire. The patients with a psychiatric illness or ongoing anxiolytic treatment or alcohol addiction were excluded from the study. Moreover, the surveys including three or more unanswered statements were regarded as invalid and not graded.

\section{Sample Size Estimation}

The main outcome measure was demonstrating the factors affecting the level of preoperative anxiety. Regarding that the preoperative anxiety rate in surgical patients was reported as $80 \pm 8 \%$ in the current literature, population proportion was taken as $80 \%$ with $\% 95$ confidence level and $8 \%$ margin of error estimating a number of 97 patients.

\section{Study Method}

For each participant, the following data were collected: age, gender, educational status, length of preoperative hospital stay, past surgical history and indication of the proposed operation. Educational status was determined in four levels as the graduation from primary, secondary, high schools and university. Any surgical intervention which had been performed under general or spinal anaesthesia was approved as a positive past surgical history. The indication of the present surgery was noted as a benign or a malignant disease. Spielberg's State-Trait Anxiety Inventory (STAI Form TX-1 and TX-2) were applied to patients thirty minutes before the transportation to operating room. The answers were recorded and calculation of scores was performed via computer aided software. The scores obtained from each scales range between 20 and 80 whereas higher points express elevated levels of anxiety ${ }^{10}$. High and low anxiety levels were defined as over and under 52 points which was the median value of state anxiety scores in this series.

\section{Statistical Analysis}

SPSS (IBM SPSS for Windows, Ver. 24) statistical package program was used for calculations. Descriptive statistics for continuous variables in this study were expressed as mean, standard deviation, minimum and maximum; categorical variables were expressed as number (n) and percentage (\%). Independent $\mathrm{T}$-test was used to compare average of measurements for patient groups and Chi-square test was employed to reveal the relation between categorical variables. The statistical significance level $(\alpha)$ was taken as $5 \%$.

\section{RESULTS}

\begin{tabular}{|c|c|c|c|c|}
\hline Parameters & Mean & Standard Deviation & Minimum & Maximum \\
\hline Age (years) & 54.1 & 11.5 & 23 & 74 \\
\hline Hospital stay (days) & 2.16 & 1.15 & 1 & 5 \\
\hline State anxiety score & 51.1 & 10.2 & 28 & 72 \\
\hline Trait anxiety score & 48.0 & 10.7 & 25 & 70 \\
\hline
\end{tabular}
Table 1. General Features of the Study Group

\begin{tabular}{|c|c|c|c|}
\hline Parameters & Groups & $\mathbf{n}$ & $\mathbf{\%}$ \\
\hline \multirow{2}{*}{ Gender } & Male & 65 & 65 \\
\cline { 2 - 4 } & Female & 35 & 35 \\
\hline \multirow{3}{*}{ Educational status } & Primary School & 20 & 20 \\
\cline { 2 - 4 } & Secondary School & 12 & 12 \\
\cline { 2 - 4 } & High School & 44 & 44 \\
\cline { 2 - 4 } & University & 24 & 24 \\
\hline \multirow{2}{*}{ Past surgical history } & Present & 32 & 32 \\
\cline { 2 - 4 } & None & 68 & 68 \\
\hline \multirow{2}{*}{ Indication of surgery } & Benign disease & 44 & 44 \\
\cline { 2 - 4 } & Malignancy & 56 & 56 \\
\hline \multirow{2}{*}{ Level of state anxiety } & Low & 44 & 44 \\
\cline { 2 - 4 } & High & 56 & 56 \\
\hline \multicolumn{2}{|c|}{ Total } & $\mathbf{1 0 0}$ & $\mathbf{1 0 0}$ \\
\hline \multicolumn{2}{|c|}{ Table 2. Data Concerning the Categorical Variables } \\
\hline \multicolumn{2}{|c}{} \\
\hline \multicolumn{2}{|c|}{}
\end{tabular}

\begin{tabular}{|c|c|c|c|c|}
\hline \multicolumn{2}{|c|}{ Parameters } & $\begin{array}{l}\text { Low Level } \\
\text { of Anxiety }\end{array}$ & $\begin{array}{l}\text { High Level } \\
\text { of Anxiety }\end{array}$ & $\mathbf{p}$ \\
\hline \multirow{2}{*}{ Gender (n) } & Male & 13 & 52 & \multirow[b]{2}{*}{$<0.001$} \\
\hline & Female & 31 & 4 & \\
\hline \multirow{4}{*}{ Education (n) } & Primary School & 17 & 3 & \multirow{4}{*}{$<0.001$} \\
\hline & Secondary School & 3 & 9 & \\
\hline & High School & 20 & 24 & \\
\hline & University & 4 & 20 & \\
\hline \multirow{2}{*}{ Past History of Surgery (n) } & Yes & 42 & 26 & \multirow{2}{*}{$<0.001$} \\
\hline & No & 2 & 30 & \\
\hline \multirow{2}{*}{ Indication of Surgery (n) } & Benign disease & 5 & 39 & \multirow{2}{*}{$<0.001$} \\
\hline & Malignancy & 39 & 17 & \\
\hline \multicolumn{2}{|c|}{ Age (Mean \pm SD, years) } & $62.3 \pm 5.98$ & $47.6 \pm 10.7$ & 0.006 \\
\hline \multicolumn{2}{|c|}{ Preoperative Hospital Stay (Mean \pm SD, days) } & $1.86 \pm 1.11$ & $2.39 \pm 1.14$ & 0.076 \\
\hline \multicolumn{2}{|c|}{ Trait Anxiety Score (Mean \pm SD) } & $38.2 \pm 6.28$ & $55.7 \pm 6.17$ & $<0.001$ \\
\hline
\end{tabular}

The mean age was $54.1 \pm 11.5$ (range $=23-74$ ) years among the whole group of patients including 65 (65\%) males and 35 $(35 \%)$ females. The majority of the patients $(n=44)$ were high school graduate. Mean preoperative length of hospital stay was $2.16 \pm 1.15$ days. Thirty-two (32\%) cases shared a past surgical history whereas 56 (56\%) patients had been diagnosed with a malignant disease. Mean score was calculated as $51.1 \pm 10.2$ by state and $48 \pm 10.7$ by trait anxiety scales, respectively. High level of anxiety was presented in $56 \%$ of the patients. Data concerning the demographic and clinical features of the patients are given in Table 1 and Table 2. Analysing the subgroups of patients, higher level of state 
anxiety score was detected in the highly educated male patients with younger age who had undergone a previous surgery, scored higher points in the trait anxiety scale and presented with the diagnosis of a benign disease $(p<0.05)$ whereas longer length of preoperative hospital stay did not reveal a significant difference in the state anxiety level (p>0.005) (table 3).

\section{DISCUSSION}

The findings of this study clearly show that the higher level of preoperative anxiety is closely associated with male sex, young age, existence of past surgical history, currently presented benign disease and high educational status. The overall prevalence of preoperative anxiety in this series was $56 \%$ as calculated by STAI score of more than 52 which was the median value. Despite of the population and surgery based variations, this finding shared similarity with the previously reported prevalence rates ranging widely between $45 \%$ and $80 \%{ }^{2-4,6,11,12}$ The recent papers in the literature mostly advocate that the prevalence of preoperative anxiety is higher in females stating that women are more sensitive to stressful events and are inclined to express their anxiety more easily.7,11-13 On the contrary, the findings of this study demonstrated higher preoperative anxiety in male patients when compared to females.

The other factors closely related and also associated with preoperative anxiety were young age and presence of a benign disease as the ground for the forthcoming surgery. The current reports claiming that the younger patients are more vulnarable to develop preoperative anxiety appear to be parallel to the findings of this study.7,8,12-14 Strongly arguing against previous studies which had announced the history of cancer as an independent risk factor for preoperative anxiety, this series revealed higher prevalence of preoperative anxiety in the patients who had developed benign diseases.6-9,13-15 The difference could be because of the common and routine practices of the thoracic surgery in which the majority of patients present malignant diseases such as lung cancer at elder ages while unexpected surgical interventions including lung and pleural biopsies or pneumothorax surgery such as bullectomy and wedge resections are performed for young patients regarding that the prevalence of pneumothorax is naturally higher for the patients aged between 19 and 25 years. Moreover, younger patients may be more distressed by predicting the potential complications and outcomes of the proposed surgery but elder patients with malignancies adapt to the situation during a relatively longer period required for diagnosis and preoperative arrangements.

In this study the prevalence of preoperative anxiety presented positive correlation with the history of previous surgical experiment. This may result from the expectation of more serious complications and outcomes than the previous less risky operation. The literature includes studies that both confirm ${ }^{14,16,17}$ and stand against this finding. ${ }^{12,15}$ The results of this study revealed that the level of anxiety elevated with the increasing level of education. Education is believed to raise awareness related to surgery and helps patients prepare themselves preoperatively. On the other hand, highly educated patients obtain detailed information about the potential complications which is likely to increase preoperative anxiety. This evidence was supported ${ }^{13,16}$ but also declined ${ }^{15-17}$ by other similar studies. Unfortunately, recent studies include more heterogeneous cohorts for whom comparisons of preoperative hospital stay were performed in intervals rather than days. ${ }^{16-18}$ However, the analysis of this study failed to demonstrate an association between preoperative anxiety and duration of preoperative hospital admission.

\section{Limitations}

The principal limitation of this study was the design as a single-centered workup including only adult patients. Cases were not classified relating the severity or stage of the causative diseases, particularly lung cancer. Moreover, the findings of this study supported some of the previous statements but also disagreed with many, proving that the surgical patients may demonstrate differential preoperative features.

\section{CONCLUSIONS}

In this study, the prevalence of preoperative anxiety was significantly associated with gender, age, educational status, presence of past surgical history and type of the underlying disease. Regarding the conflicting results obtained in dissimilar populations and different surgical cohorts, individual assessment of each surgical patient is necessary in order to perform a valid risk analysis of preoperative anxiety.

\section{REFERENCES}

[1] Mulugeta H, Ayana M, Sintayehu M, et al. Preoperative anxiety and associated factors among adult surgical patients in Debre Markos and Felege Hiwot referral hospitals, Northwest Ethiopia. BMC Anesthesiology 2018;18(1):155-24.

[2] Rosiek A, Kornatowski T, Rosiek-Kryszewska A, et al. Evaluation of stress intensity and anxiety level in preoperative period of cardiac patients. Article ID 1248396, BioMed Res Int 2016;2016:1-8.

[3] Lemosa MF, Lemos-Netoa SV, Barrucandb L, et al. Preoperative education reduces preoperative anxiety in cancer patients undergoing surgery: usefulness of the self-reported Beck anxiety inventory. Rev Bras Anestesiol 2019;69(1):1-6.

[4] Del Aguila E, Martinez JR, Pablos JL, et al. Personality traits, anxiety and self-esteem in patients seeking cosmetic surgery in Mexico City. Plast Reconstr Surg Glob Open 2019;7(10):e2381.

[5] Baghele A, Dave N, Dias R, et al. Effect of preoperative education on anxiety in children undergoing day-care surgery. Indian J Anaesth 2019;63(7):565-70.

[6] Majumdar JR, Vertosick EA, Cohen B, et al. Preoperative anxiety in patients undergoing outpatient cancer surgery. Asia Pac J Oncol Nurs 2019;6(4):440-5. 
[7] Wetsch WA, Pircher I, Lederer W, et al. Preoperative stress and anxiety in day-care patients and inpatients undergoing fast-track surgery. British $J$ Anaes 2009;103(2):199-205.

[8] Chow CHT, Rizwan A, Xu R, et al. Association of temperament with preoperative anxiety in pediatric patients undergoing surgery. JAMA Network Open 2019;2(6):e195614.

[9] Williams H, Jajja MR, Baer W, et al. Perioperative anxiety and depression in patients undergoing abdominal surgery for benign or malignant disease. J Surg Oncol 2019;120(3):389-96.

[10] Spielberger CD, Gorsuch RL. Manual for the State-Trait Anxiety Inventory (Form Y) ("Self-Evaluation Questionnaire). Palo Alto, CA: Consulting Psychologists Press 1983.

[11] Socea SD, Abualhasan H, Magen 0, et al. Preoperative anxiety levels and pain during cataract surgery. Current Eye Research 2019: p. 1-6.

[12] Ralph N. Current opinion about surgery-related fear and anxiety. J Periop Nurs 2018;31 (4):1-5.
[13] Stoddard JA, White KS, Covino NA, et al. Impact of a brief intervention on patient anxiety prior to day surgery. J Clin Psychol Med Set 2005;12 (2):99-110.

[14] Kuzminskaite V, Kaklauskaite J, Petkeviciute J. Incidence and features of preoperative anxiety in patients undergoing elective non-cardiac surgery. Acta Med Lituannica 2019;26 (1):93-100.

[15] Bedaso A, Ayalew M. Preoperative anxiety among adult patients undergoing elective surgery: a prospective survey at a general hospital in Ethiopia. Patient Safety in Surgery 2019;13:18.

[16] Stamenkovic DM, Rancic NK, Latas MB, et al. Preoperative anxiety and implications on postoperative recovery: What can we do to change our history? Minerva Anestesiologica 2018;84 (11):1307-17.

[17] Tulloch I, Rubin JS. Assessment and management of preoperative anxiety. Journal of Voice 2019;33 (5):6916.

[18] Ebirim L, Tobin M. Factors responsible for pre-operative anxiety in elective surgical patients at a university teaching hospital: a pilot study. The Internet Journal of Anesthesiology

2010;29(2):12-8 